\title{
Acute suppurative thyroiditis caused by thyroid papillary carcinoma in the right thyroid lobe of a healthy woman
}

\author{
Hazuki Otani ${ }^{1}$, Masakazu Notsu ${ }^{1 *}$ (D), Sayo Koike ${ }^{1}$, Miwa Morita ${ }^{1}$, Masahiro Yamamoto ${ }^{1}$, Mika Yamauchi ${ }^{1}$, \\ Takahumi Fuchiwaki ${ }^{2}$, Ichiro Morikura ${ }^{2}$, Noriaki Aoi ${ }^{2}$, Hideyuki Kawauchi ${ }^{2}$, Teruaki Iwabashi ${ }^{3}$, Asuka Araki ${ }^{3}$, \\ Noriyoshi Ishikawa ${ }^{3}$, Riruke Maruyama ${ }^{3}$ and Toshitsugu Sugimoto ${ }^{1}$
}

\begin{abstract}
Background: The thyroid gland is resistant to microbial infection, because of its organ characteristics such as encapsulation, iodine content, and rich blood supply. Therefore, acute suppurative thyroiditis (AST), as a bacterial infection of the thyroid gland, is rarely seen. AST typically takes places on the left side the neck region in children, because of the coincidence of the left piriform sinus fistula, as a most common route of infection. AST is also usually seen in immunocompromised hosts. Herein, we report a rare case of AST in the right thyroid lobe of adult woman without any immunocompromised condition.

Case presentation: A 59-year-old woman was introduced to our hospital for the further examination with fever, sore throat, and right anterior neck swelling. The patient appeared not to be immunodeficient. Neck ultrasonography showed a 47-mm, hypoechoic, heterogeneous nodule with ill-defined margins and irregular form, suggesting a right thyroid malignant nodule. Fine needle aspiration (FNA) biopsy specimen revealed numerous number of neutrophils in the background without nuclear atypia. Based on the clinical course and cytology, AST was confirmed to be diagnosed. Complete response was obtained by an intravenous administration of antimicrobial agents within a week. Image findings such as CT scan did not show any piriform sinus fistula. Four months later, neck ultrasonography showed a significant decrease in size of the nodule in the right thyroid gland to $27 \mathrm{~mm}$, but the lesion still resembled a malignant nodule. So, FNA was repeated again and cytological examination confirmed papillary thyroid carcinoma (PTC). The patient subsequently underwent total thyroidectomy and bilateral level D1 lymph node dissection. Histological findings revealed a 20-mm PTC in the right lobe with sternothyroid muscle invasion of the tumor.

Conclusions: This report represents a rare case of AST associated with PTC on the right side of thyroid gland, found in a healthy adult woman. The reason why AST coincided with malignant thyroid tumor is unclear. We have to take it into our account that malignant tumor may exist in the background when AST is identified on the right side of thyroid gland with a healthy subject.
\end{abstract}

Keywords: Acute suppurative thyroiditis, Papillary thyroid carcinoma, Fine needle aspiration, Bacterial infection, Piriform sinus fistula, Malignant tumor

\footnotetext{
* Correspondence: mnotsu25@med.shimane-u.ac.jp

${ }^{1}$ Department of Internal Medicine 1, Shimane University Faculty of Medicine,

89-1 Enya-cho, Izumo, Shimane 693-8501, Japan

Full list of author information is available at the end of the article
}

(c) The Author(s). 2018 Open Access This article is distributed under the terms of the Creative Commons Attribution 4.0 International License (http://creativecommons.org/licenses/by/4.0/), which permits unrestricted use, distribution, and reproduction in any medium, provided you give appropriate credit to the original author(s) and the source, provide a link to the Creative Commons license, and indicate if changes were made. The Creative Commons Public Domain Dedication waiver (http://creativecommons.org/publicdomain/zero/1.0/) applies to the data made available in this article, unless otherwise stated. 


\section{Background}

Acute suppurative thyroiditis (AST) is a result of bacterial infection and represents a relatively rare condition in the thyroid gland. The thyroid gland is resistant to microbial infection, because of factors such as its encapsulation, iodine content, and rich blood supply $[1,2]$. As a result, AST rarely develops in healthy individuals. Typically, AST is more likely to occur in children and in the left side of the neck. In $80 \%$ of patients with AST, the age at onset is before 10 years old (with $30 \%$ between birth and 2 years old), and only $8 \%$ occur in adulthood [3]. The presence of a left piriform sinus fistula has been reported as important, as a potential route of infection [4]. AST on the right side of thyroid gland in adults is thus rarely seen. We encountered a case of AST in the right lobe of the thyroid in a healthy woman. Moreover, AST developed against a background of papillary thyroid carcinoma (PTC).

\section{Case presentation}

A 59-year-old woman was introduced to our hospital with a 4-week history of fever, sore throat, and swollen neck, after first visiting a primary-care physician and receiving antibiotics. She had no chronic diseases and appeared not to be to be in an immunocompromised state (she was well-nourished, had no diabetes and did not use any steroids, and human immunodeficiency virus (HIV) antibody was negative). On examination, a nodule showing pain, erythematous changes, and warmth was palpable in the anterior neck on the right side. The nodule showed limited mobility and no adjacent lymphadenopathy. The patient had no medical history of note, and no infectious symptoms such as cough, headache, or abdominal or joint pain were identified, other than the neck pain. Axillary temperature was $36.9^{\circ} \mathrm{C}$, heart rate was 109 beats/min, and blood pressure was 169/88 $\mathrm{mmHg}$. Table 1 shows the results of laboratory examination at the first visit (day X). Hematological tests revealed a high erythrocyte sedimentation rate $(102 \mathrm{~mm} / \mathrm{hr})$ and elevated concentrations of C-reactive protein $(10.4 \mathrm{mg} / \mathrm{dL})$. A slight increase in thyroid-stimulating hormone (TSH) was also identified, showing subclinical hypothyroidism. Negative results were obtained for thyroglobulin antibody and serum thyroglobulin level was high $(3590 \mathrm{ng} / \mathrm{mL})$. Neck ultrasonography showed a 47-mm nodule, with ill-defined margins, irregular form, and a hypoechoic, heterogeneous appearance, in the area of the right thyroid, suggesting thyroid malignancy (Fig. 1a). Contrast-enhanced computed tomography $(\mathrm{CT})$ confirmed a $37 \times 37 \times 42-\mathrm{mm}$ nodule within the right thyroid lobe at the middle and lower pole. The thyroid mass resulted in displacement of the trachea toward the left and showed enhancement in the peripheral area of the nodule (Fig. 1b). No signs of metastasis were apparent, including in the lungs and bone.

Table 1 Results of laboratory testing at the time of first visit

(day $X)$

\begin{tabular}{|c|c|c|}
\hline$\overline{W B C}$ & 7270 & $/ \mu \mathrm{L}$ \\
\hline neutro & 67.3 & $\%$ \\
\hline eos & 0.3 & $\%$ \\
\hline baso & 0.4 & $\%$ \\
\hline mono & 6.6 & $\%$ \\
\hline lymph & 25.4 & $\%$ \\
\hline $\mathrm{RBC}$ & $458 \times 10^{4}$ & $/ \mu \mathrm{L}$ \\
\hline $\mathrm{Hg}$ & 14.2 & $\mathrm{~g} / \mathrm{dL}$ \\
\hline $\mathrm{Hct}$ & 41.6 & $\%$ \\
\hline Plt & $24.5 \times 10^{4}$ & $/ \mu \mathrm{L}$ \\
\hline ESR & 102 & $\mathrm{~mm}$ \\
\hline Alb & 4.2 & $\mathrm{~g} / \mathrm{dL}$ \\
\hline T-Bil & 1.0 & $\mathrm{mg} / \mathrm{dL}$ \\
\hline AST & 22 & $U / L$ \\
\hline ALT & 17 & $\mathrm{U} / \mathrm{L}$ \\
\hline$\gamma$-GTP & 22 & $U / L$ \\
\hline LDH & 233 & $U / L$ \\
\hline BUN & 9.9 & $\mathrm{mg} / \mathrm{dL}$ \\
\hline Crea & 0.52 & $\mathrm{mg} / \mathrm{dL}$ \\
\hline CK & 71 & $U / L$ \\
\hline CRP & 10.4 & $\mathrm{mg} / \mathrm{dL}$ \\
\hline $\mathrm{Na}$ & 141 & $\mathrm{mEq} / \mathrm{L}$ \\
\hline K & 4.2 & $\mathrm{mEq} / \mathrm{L}$ \\
\hline $\mathrm{Cl}$ & 105 & $\mathrm{mEq} / \mathrm{L}$ \\
\hline FPG & 105 & $\mathrm{mg} / \mathrm{dL}$ \\
\hline $\mathrm{HbA1c}$ & 6.1 & $\%$ \\
\hline HIV antibody & negative & \\
\hline Free T3 & 2.4 & $\mathrm{pg} / \mathrm{mL}$ \\
\hline Free T4 & 1.0 & $\mathrm{ng} / \mathrm{dL}$ \\
\hline TSH & 4.55 & $\mu \mathrm{U} / \mathrm{mL}$ \\
\hline TPO Ab & $<2.55$ & $\mathrm{IU} / \mathrm{mL}$ \\
\hline $\operatorname{Tg} A b$ & $<6.12$ & $\mathrm{IU} / \mathrm{mL}$ \\
\hline $\mathrm{Tg}$ & 3590 & $\mathrm{ng} / \mathrm{mL}$ \\
\hline
\end{tabular}

ESR erythrocyte sedimentation rate, $F P G$ fasting plasma glucose, $H b A 1 c$ hemoglobin A1C, TSH thyroid-stimulating hormone, $T g$ thyroglobulin

Fine needle aspiration (FNA) was performed on the first visit. Findings on cytological examination were suggestive of AST, because little nuclear atypia was evident, and numerous number of neutrophils were seen in the background (Fig. 2). No PTC was apparent at that time. Based on the clinical course and cytology, AST was confirmed to be diagnosed and the patient was admitted to the endocrinology department.

The clinical course is shown in Fig. 3. Antibiotic therapy produced complete response, with rapid improvement within 1 week. Serum thyroglobulin level tended 

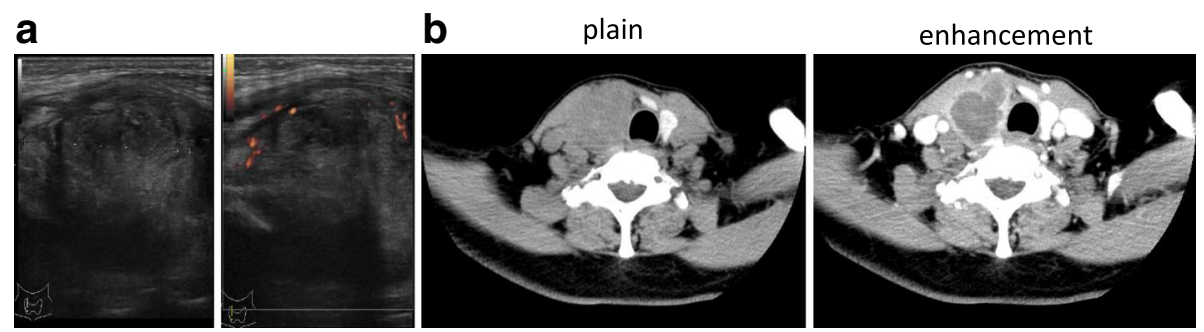

Fig. 1 Ultrasonography on day $X$ reveals a hypoechoic lesion with ill-defined margins and irregular form, appearing avascular and heterogeneous (a). Computed tomography of the neck on admission (day $X+5$ ) also reveals a low-density lesion in the right thyroid gland, $37 \times 37 \times 42 \mathrm{~mm}$ in size with enhancement in the marginal area (b)

to decrease $(528 \mathrm{ng} / \mathrm{mL}$ on day $\mathrm{X}+8 ; 47.3 \mathrm{ng} / \mathrm{mL}$ on day $\mathrm{X}+34)$. Blood cultures on day $\mathrm{X}+6$ yielded negative results. CRP concentration was just $0.71 \mathrm{mg} / \mathrm{dL}$ on day $\mathrm{X}+8$, and the patient was discharged with complete disappearance of symptoms. A barium swallow study was performed after CRP turned negative, but no fistula of the pyriform sinus was detected (Fig. 4). Neck ultrasonography 4 months after the onset showed that the nodule in the right thyroid gland had shrunk to $27 \mathrm{~mm}$ in diameter, but still showed like malignancy. FNA was repeated, and cytological examination revealed overlapping cell clusters, high nuclear density, nuclear grooves, and intranuclear cytoplasmic inclusion bodies, leading to a diagnosis of PTC (Fig. 2c). The patient subsequently underwent total thyroidectomy and bilateral level D1 lymph node dissection. Histological examination revealed a $20-\mathrm{mm}$ PTC in the right lobe with invasion to the sternothyroid muscle, and a 16-mm PTC in the left lobe (Fig. 5). PTC in the left lobe was not found by

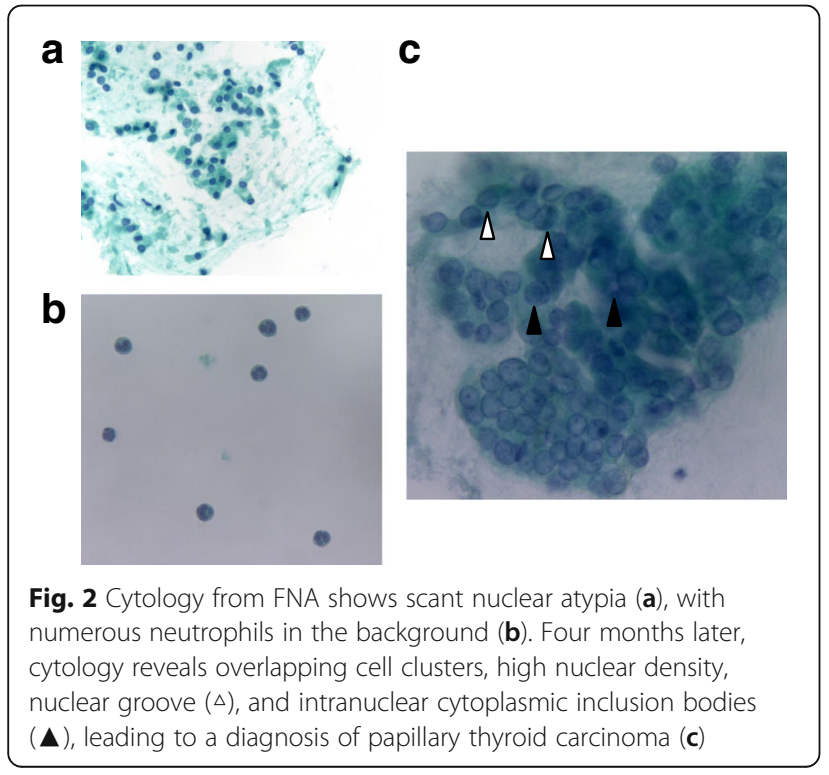

ultrasonography before surgery. One possible reason is inhomogenous thyroid grand by adenomatous goiter, but it is unclear why left PTC was not found. Histological examination first detected it after the surgery. The right PTC was well-differentiated, but with large necrotic regions. The left PTC was close to the sternothyroid muscle. No lymph nodes contained metastatic PTC. Cord-like tissue considered as fistulous tract was not found to communicate with the right lobe and the hypopharynx. Pathological staging was pT3N0. Postoperatively, the patient received radioactive iodine ablation.

\section{Discussion and conclusions}

This represents a rare case of right-sided AST concomitant with PTC, found in an adult woman who did not appear immunocompromised and did not have any other foci of infection. In addition, we could not find any evidence of piriform sinus fistula, even after resolution of inflammation.

Some reports have described concomitant AST and thyroid cancer. One case developed AST after FNA of a PTC, and was therefore considered as infection secondary to needle aspiration [5]. Haddad and colleagues reported a case of AST in a patient with ischemic heart failure and type one diabetes mellitus [6]. In another case, a pregnant woman who had given birth by Cesarean section was diagnosed with AST after thyroidectomy [7]. The present case clearly differed from these cases in the lack of a clear cause of AST. The reasons for the AST occurring with malignant tumor in the present case remains unclear, as this woman showed no sign of infectious disease and was not immunocompromised, and no piriform sinus fistula was present. Because the AST and PTC showed identical locations, the PTC could easily be imagined to be infected with bacteria, but the mechanisms were not clear. A previous report [8] suggested that an abnormal blood supply from the PTC could facilitate infection, and an abnormal blood supply from malignant tumor may thus have resulted in infection in our case. 


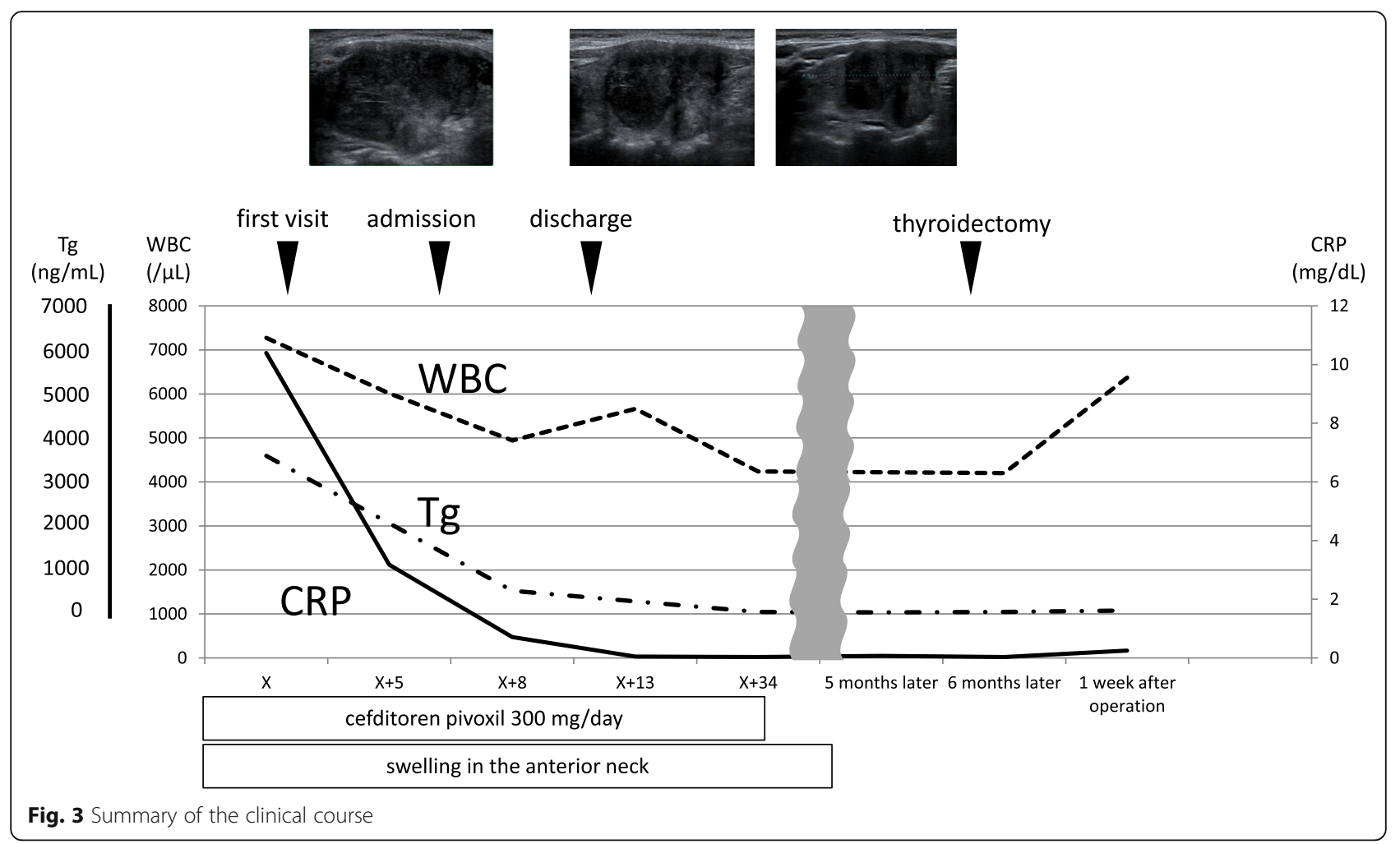

Takai et al. first proposed the presence of a left piriform sinus fistula as a route of infection [4]. In the present case, however, we could not find any sign of a piriform sinus fistula. Repeated inflammation may result in adhesions within the fistula, and potentially masking the fistula in cases with repeated episodes of infection. However, this patient had presented with the first episode of inflammation, so fistula as the route of infection seems unlikely in our case. We attempted to culture

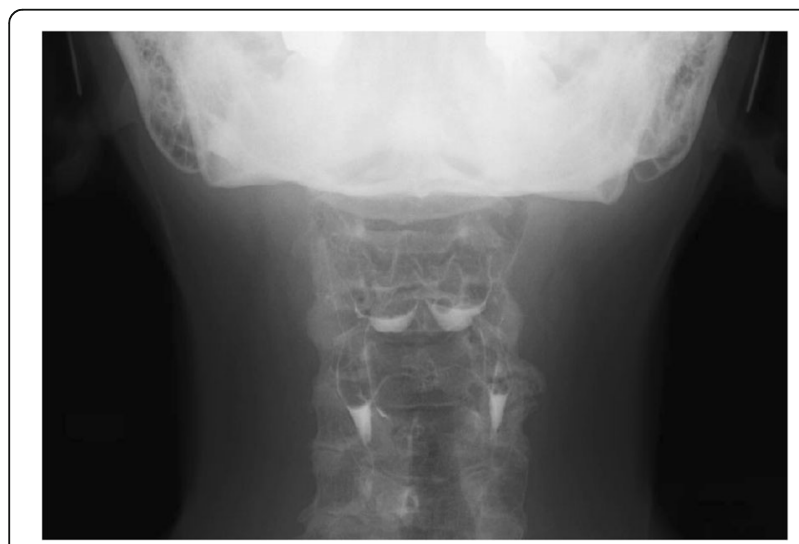

Fig. 4 Barium swallow study (frontal view) does not show any fistula from the apex of the pyriform recess bacteria from the thyroid nodule to provide insights into the source of infection, but the results were negative. Cultivation of bacteria probably failed because the patient had been given antibiotics for about 1 week before the sample was obtained for cultivation.

In $80 \%$ of AST patients, the age at onset is less than 10 years old, with $30 \%$ occurring between birth and 2 years old, and only $8 \%$ of cases occur in adulthood [3]. An overview of 109 cases of AST reported that 85 patients had first experienced AST in childhood [9]. Patients diagnosed with AST are likely to have experienced repeated inflammation of the neck, but our patient had no any past history of neck infections. The same overview also reported that $92 \%$ of patients showed left-sided infection, with bilateral infection in only $2 \%$ [9]. Kingsbury described poor development of the right branchial arch in the prenatal period [10]. Park reported that piriform fistula is more likely on the left than on the right, because the pharyngeal arch is drawn out to the nasal side during formation of the aortic arch by the left fourth branchial arch [11], which is why AST mostly occurs in the left lobe of the thyroid. AST on the right side of thyroid gland in adults is rarely seen. Those cases of right-sided AST in adults that have been reported have shown backgrounds of infection such as infective endocarditis $[8,12]$ or miliary tuberculosis [13], or immunocompromise due to steroid use or HIV 

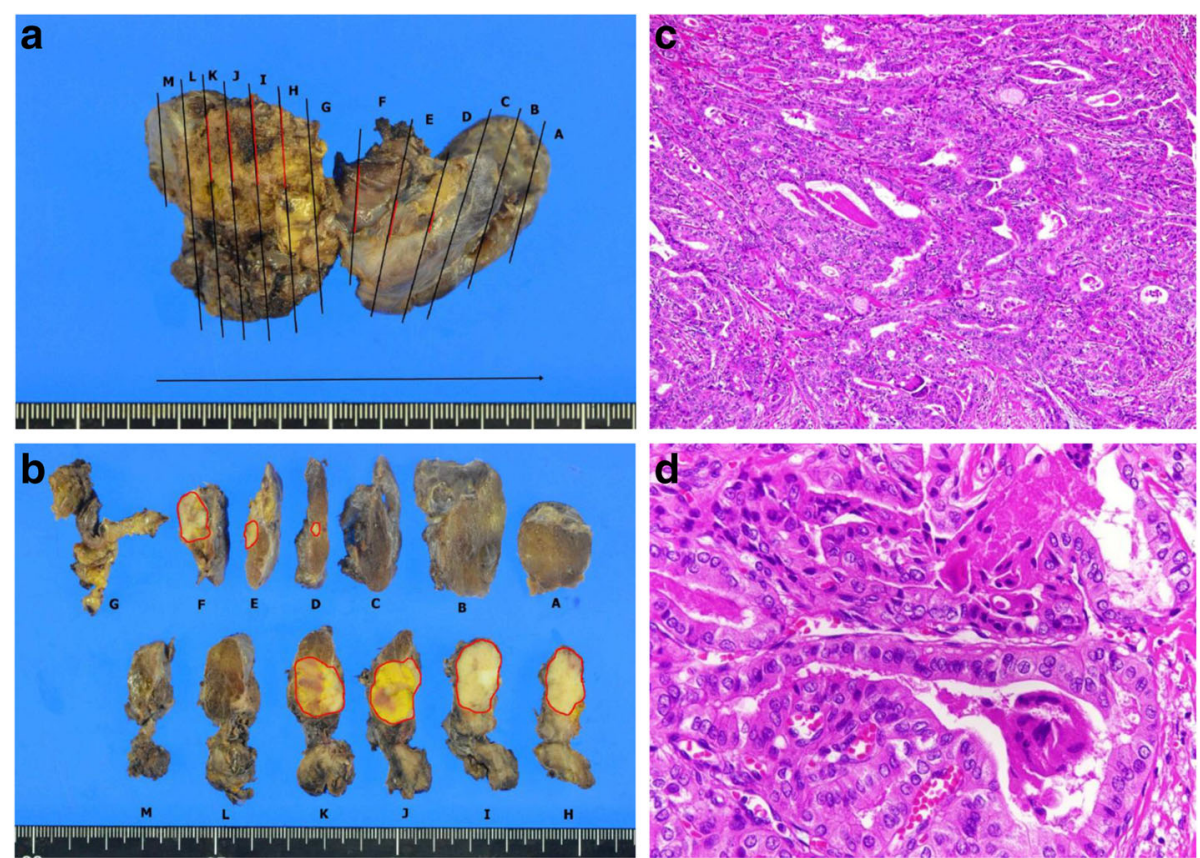

Fig. 5 Gross (a and $\mathbf{b}$ ) and microscopic (c and $\mathbf{d}$ ) appearance of papillary carcinoma of the thyroid

infection $[14,15]$. In our case, the patient was HIVnegative and did not have any other infection or underlying diseases and was thus not considered to be in a compromised condition. The cause of AST remains unknown, but the possibility of some involvement of the PTC must be considered.

This case was uncommon in terms of age and lesion location, which made differentiation of AST from malignancy difficult in the early phase. A paper by Lin reviewed 30 patients with malignant thyroid cancer who showed clinical features similar to AST [16]. The significant characteristics of malignant thyroid tumor were clearly indicated as follows: 1 ) higher age at diagnosis $(P=0.0155) ; 2)$ presence of dysphonia $(P=0.0325)$; $3)$ right lobe involvement $(P=0.0151)$; 4$)$ larger thyroid mass $(P=0.0013)$; 5) presence of anemia $(P=0.0075)$; and 6) sterile pus culture $(P=0.0013)$. Our case met 4 of these 6 clinical features suggestive of malignancy. The symptoms and signs of malignant thyroid tumor may mimic those of infectious thyroiditis, so we should be careful in diagnosing AST or aggressive malignant tumor. Long-term follow-up using both ultrasonography and FNA is also necessary. We obtained findings indicating PTC 5 months after identifying the presence of AST, on the third cytological examination. No findings even suggestive of PTC were evident from the first cytological examination, with relatively few variant epithelial cells and numerous leukocytes. One possibility was that we sampled a location where lymphocytes were gathered or that was necrotic.
We encountered a case of AST in the right lobe of a healthy woman. AST can develop with thyroid malignant tumor, so we have to take it into our account that malignant tumor may exist in the background when AST is identified on the right side of thyroid gland with a healthy subject.

\section{Abbreviations}

AST: Acute suppurative thyroiditis; ESR: Erythrocyte sedimentation rate; FNA: Fine needle aspiration; FPG: Fasting plasma glucose; HbA1c: Hemoglobin A1c; PTC: Papillary thyroid carcinoma; Tg: Thyrogloblin; TSH: Thyroid-stimulating hormone

\section{Availability of data and materials}

All data generated or analysed during this study are included in this published article.

\section{Authors' contributions}

$\mathrm{HO}$ and MN mainly examined and determine how to treat the patient and were major contributors in writing the manuscript. SK and MM also examined the patients. MY, MY and TS gave many advices during treating the patients. TF, IM, NA and HK performed the patient's operation. TI, AA, NI and RM performed the histological examinations of the thyroid. All authors read and approved the final manuscript.

Ethics approval and consent to participate

Not applicable.

\section{Consent for publication}

Written informed consent was obtained from subjects for publication of this report. A copy of the written consent is available for review upon requests.

Competing interests

The authors declare that they have no competing interests. 


\section{Publisher's Note}

Springer Nature remains neutral with regard to jurisdictional claims in published maps and institutional affiliations.

\section{Author details}

${ }^{1}$ Department of Internal Medicine 1, Shimane University Faculty of Medicine, 89-1 Enya-cho, Izumo, Shimane 693-8501, Japan. ²Department of Otorhinolaryngology, Shimane University Faculty of Medicine, 89-1 Enya-cho, Izumo, Shimane 693-8501, Japan. ${ }^{3}$ Department of Pathology, Shimane University Faculty of Medicine, 89-1 Enya-cho, Izumo, Shimane 693-8501, Japan

Received: 18 January 2018 Accepted: 6 May 2018

Published online: 15 May 2018

\section{References}

1. Pearce EN, Farwell AP, Braverman LE. Thyroiditis. N Engl J Med. 2003;348: 2646-55.

2. Singer PA. Thyroiditis. Acute, subacute, and chronic. Med Clin North Am. 1991;75:61-77.

3. Miyauchi A, Matsuzaka F, Takai S, Kuma K, Kosaki G. Priform sinus fistula. A route of infection in acute suppurative thyroiditis. Arch Surg. 1981;116:66-9.

4. Takai S, Miyauchi A, Matsuzaka F, Kuma K, Kosaki G. Internal fistula as a route of infection in acute suppurative thyroiditis. Lancet. 1979;1:751-2.

5. Chen HW, Tseng FY, Su DH, Chang YL, Chang TC. Secondary infection and ischemic necrosis after fine needle aspiration for a painful papillary thyroid carcinoma: a case report. Acta Cytol. 2006;50:217-20.

6. Haddad FH, Malkawi OM, Omari AA, Izzat AS, Khassrof HM, Faiad LM, et al. Diabetes and infarcted papillary thyroid cancer. Saudi Med J. 2002;23:467-70.

7. George MM, Goswamy J, Penney SE. Embolic suppurative thyroiditis with concurrent carcinoma in pregnancy: lessons in management through a case report. Thyroid Res. 2015;8:3.

8. Inoue K, Kozawa J, Funahashi T, Nakata Y, Mitsui E, Kitamura T. Right-sided acute suppurative thyroiditis caused by infectious endocarditis. Intern Med. 2011;50:2893-7.

9. Cases JA, Wenig BM, Silver CE, Surks MI. Recurrent acute suppurative thyroiditis in an adult due to a fourth branchial pouch fistula. J Clin Endocrinol Metab. 2000;85:953-6.

10. Kingsbury BF. On the fate of the ultimobranchial body within the human thyroid gland. Anat Rec. 1935;61:155-73.

11. Park SW, Han MH, Sung MH, Kim IO, Kim KH, Chang KH, et al. Neck infection associated with pyriform sinus fistula: imaging findings. Am J Neuroradiol. 2000;21:817-22.

12. Cabizuca CA, Bulzico DA, de Almeida MH, Conceição FL, Vaisman M. Acute thyroiditis due to septic emboli derived from infective endocarditis. Postgrad Med J. 2008:84:445-6.

13. Nierwiand Y, Tan KY, Elte JW. Miliary tuberculosis presenting with thyrotoxicosis. Postgrad Med J. 1992;68:677-9.

14. Teckie G, Bhana SA, Tsitsi JM, Shires R. Thyrotocosis followed by hypothyroidism due to suppurative thyroiditis caused by Nocardia brasiliensis in a patient with advances acquired immunodeficiency syndrome. Eur Thyroid J. 2014;3:65-8.

15. Golshan MM, McHenry CR, de Vente J, Kalajyain RC, Hsu RM, Tomashefski JF. Acute suppurative thyroiditis and necrosis of the thyroid gland: a rare endocrine manifestation of acquired immunodeficiency syndrome. Surgery. 1997;121:593-6.

16. Lin KD, Lin JD, Huang MJ, Huang HS, Jeng LB, Ho YS. Acute suppurative thyroiditis and aggressive malignant thyroid tumors: differnces in clinical presentation. J Surg Oncol. 1998;67:28-32.

\section{Ready to submit your research? Choose BMC and benefit from:}

- fast, convenient online submission

- thorough peer review by experienced researchers in your field

- rapid publication on acceptance

- support for research data, including large and complex data types

- gold Open Access which fosters wider collaboration and increased citations

- maximum visibility for your research: over $100 \mathrm{M}$ website views per year

At BMC, research is always in progress.

Learn more biomedcentral.com/submissions 